\title{
Research on International Project Contract Management and Claim
}

\author{
Xiaoliang Li \\ Sinohydro Tianjin Engineering Co., Ltd, Tianjin, 300000
}

Keywords: International Project, Contract Management, Claim Research

\begin{abstract}
This paper discuss the status and function of contract management and claim in international project management, introduces the main work contents, working procedures and some techniques of contract management and claim in international project management, and points out that in these complicated and complicated work Should pay attention to the problem. Through the analysis of Chinese construction projects in the field of contract, contract management and claims the status quo, to identify the existing problems and causes. Combining with the mature experience of contract management and claim in international engineering, the methods and measures to solve the problem are put forward.
\end{abstract}

\section{Introduction}

Since 1979, Chinese enterprises to develop international engineering market, has been more than 20 years of history. As of the end of August 2001, China has accumulated more than 20 years of foreign contracted projects and labor cooperation contract amount of 120.64 billion US dollars, completed turnover of 87.49 billion US dollars. Including foreign contracted projects, including foreign economic cooperation in Chinese foreign economic and trade and even the national economy plays an increasingly important role by the relevant state departments and the community wide attention and strong support. In the big companies in the Western monopoly of this big market, our company overcoming all obstacles, courageously open up, and achieved great results. Since 1995, China has more than 20 enterprises each year to enter the ranks of the world's 225 large contractors, Chinese engineering consulting firms have begun to enter the international engineering consulting market.

\section{Strengthen the Construction Project Construction Contract and the Significance of the Management}

The requirements of the law of market economy. With the development and perfection of the market economic mechanism, the government management department is required to break the traditional concept of restraint, change the government function, more application of legal, regulatory and economic means to regulate and manage the market, rather than using administrative orders to intervene in the market; The main body of the market, the construction of production and management activities, must be in accordance with market rules, improve and improve the internal management system, in which the contract management system is one of the key elements of its management system.

Regulate the needs of market behavior. From the construction of market economic activities and trading behavior, the participation of the parties involved in the construction of the lack of market economy must be the concept of legal and integrity awareness, unfair competition behavior occurs, contractual contract self-discipline is poor, coupled with the market mechanism is difficult to play 
Should be the function, thus exacerbating the construction of market economic order chaos. Therefore, the government administrative departments must strengthen the construction project construction contract management, regulate the main market transactions, and promote the healthy and stable development of the construction market.

The construction industry meets the needs of international competition. With the construction market will be fully open. Foreign construction contractors to enter the construction market in China, if the owners do not deal with the main body of the market, still blindly lower prices, pressure period and the requirements of the project, and cause trade disputes. Therefore, the contractors should establish an international awareness as soon as possible, strengthen the sense of claim, improve the level of claims management, follow the rules of the market and international practice, strengthen the construction project construction contract management.

\section{Current Situation and Countermeasures of Construction Contract and Construction Claim Management}

First, Chinese law is not yet sound, there are laws not very serious, the legal environment of the contract is not very good, people are not accustomed to using legal means and contract measures to solve the problem. Contract signing and implementation of many problems, the effectiveness of contract management is not significant, the level is also difficult to improve. Will directly affect the realization of the project construction goals, and then bring the owners of the inevitable loss.

Second, the construction contract performance is low, serious breach of contract. Mainly in the construction of the owners do not in accordance with the contract agreed to pay the progress of the project; construction project after the completion of acceptance, the contractor is not timely for the completion of the settlement procedures, and even some owners have been using engineering for many years, The formation of the construction market serious arrears of the project stubborn disease; the current construction market is not standardized, the contractor is not scheduled according to the organization of construction, mutual passing, the formation of extension works, affecting the construction market environment.

Third, part of the construction contract documents on the performance of the two sides agreed to the rights and obligations unfair. From the implementation of the construction contract text, the vast majority of the terms of the construction contract is to the contractor to develop, most of which stressed the obligations of the contractor, the owners of the constraints less, especially for owners of default, compensation and other aspects The agreement is not specific, but also the lack of effective punishment. Generally speaking, the normal risk of contracting the project contract always exists, and the fierce competition and non-standard management of the current construction market, a large number of construction teams and construction scale serious imbalance, resulting in the owners in the construction project contract dominate, put forward some Harsh and unequal conditions, transfer their own risk to the contractor.

Fourth, the contract claims work difficult to achieve. The claim is the right of the contract and the law to the loss of the person, for the contractor is a means to protect themselves, safeguard the legitimate rights and interests, to avoid losses, increase profits. And the construction of the market over-competition, unequal contract conditions and other issues, to the claim work caused a lot of interference factors, coupled with the contractor self-protection awareness is poor, weak claims, resulting in contract claims difficult to carry, the victims are often contractors The

Fifth, the contract is not standardized, not unified. The State Administration for Industry and Commerce and the Ministry of Construction to strengthen and standardize the construction of the contract management, developed a "construction project construction contract model" to fully 
reflect the responsibilities, rights and risks. But some owners and contractors can not be in full accordance with the contract model text signed a contract, using some homemade, non-standard text to sign. For the owners mainly through homemade, general, vague text conditions, evasive, pass the project risk.

Familiar with and grasp the relevant construction laws and regulations. The laws and regulations involved in the construction phase are the legal basis for protecting the interests of both parties.

In-depth study and comprehensive analysis of tender documents. After the contractor obtains the tender documents, it should be in-depth study and comprehensive analysis, a correct understanding of the tender documents, the owner's intention and requirements. To analyze the details of the bidders, detailed examination of drawings, review the amount of engineering, analysis of the contract text, study the tender strategy to reduce the risk after the signing of the contract.

Signed a perfect construction contract. It is based on the "interests of the principle" as a contractor would rather not contract the project, can not sign an unfavorable, independent bear too much risk of the contract. There are many risks in the construction process, the question is who will bear. Reducing or avoiding risk is the focus of negotiating construction contracts. Through the contract negotiations, so that the contract can reflect the balance of rights and interests of both sides of the balance and fairness, the inevitable risk, by the two sides a reasonable share.

Grasp the factor market price dynamics. Factor market price changes are often encountered risks. In the tender offer, we must grasp the market price of the factors, so that accurate and reasonable offer to reduce the risk of potential factors. However, in the tender offer tend to price changes in the factor market is not expected, inadequate consideration, especially the adjustable price contract, to control the risk, we must always grasp the changes in the price of the factor market, in accordance with the contract to adjust the contract price in order to reduce the risk.

\section{Project Claims and Counterclaims}

The so-called claim opportunity is due to the other's fault or negligence, may result in additional loss of their own events. For construction, any loss is necessarily reflected in the cost and duration of the project. From the type of claims, there are two types of claims and claims. The root cause of the additional loss is caused by one or several interference events, so the analysis of the interference event can be used to predict possible claims. Through the project cost analysis and duration analysis, both can find the opportunity to claim, but also for the formal claims to provide accurate and reliable basis for the calculation. Project cost analysis, construction schedule analysis, and interference event analysis are the main single interrelated approaches to contractor discovery of claim opportunities.

Friendly negotiation is the contract in accordance with the provisions of the contract, put the truth in fact, to clarify the responsibility to discuss, mutual concessions, so that the dispute is resolved. It is the most basic, the most common and most effective way, it has a simple way, time is short, the two sides do not need additional costs, the advantages of harmonious atmosphere. The mediation solution was the rapid development of engineering claims dispute settlement in the 1990s. Like the Dispute Review Council, mediation is also binding and must be written into the contract. Dispute mediation usually involves a conciliator who is agreed by both parties, usually by an arbitrator or a judge, and a plenipotentiary of both parties. The parties' positions, considerations and recommendations are communicated through the mediator, and the mediator generally focuses on the actual amount of the dispute and helps the parties to reach an economic or non-economic solution. Through several rounds of secret meetings, and finally reached a settlement agreement. The advantages of dispute mediation are: easy to arrange quickly; not expensive; to avoid 
unnecessary confrontation and conflict; both sides can control the mediation process; success rate of up to $80 \%$; confidentiality without affecting the image of both sides; particularly suitable for solving multi-party disputes.

Arbitration or litigation is the last resort to rely on legal decisions to resolve a contract dispute. When the contract dispute can not be agreed through mediation, according to the provisions of the project contract, the dispute submitted to the international arbitration authorities for arbitration. Arbitration as a formal legal process, the ruling on both sides of the dispute are legally binding. Arbitration has the advantage of impartiality and authority for the arbitration results of the major construction claims dispute. However, due to the complexity of the international arbitration, involving a large number of institutions, the amount of the ruling is huge, so it takes a long time to pay a huge amount of arbitration Costs and claims. The cost of submitting an arbitration dispute is not just an arbitration fee, but also a lot of agency and attorneys' fees, related evidence, information, transportation, etc., so that the final claim settlement costs generally exceed $25 \%$ of the claim. And even the formation of such a point of view: the dispute once submitted to international arbitration, often only the lawyer is the winner, the two sides will be a lose-lose dispute.

In a specific engineering contract, the manner in which the dispute is to be settled should be determined according to the nature of the project and the manner of the contract. The Dispute Review Council is more suitable for long-term complex large-scale projects or underground construction projects. Mediation is suitable for small and medium sized projects. In a contract, there is no need to use all the dispute resolution techniques, but should start from the lower preventive measures, as far as possible through consultation and negotiation to solve the problem.

\section{Conclusion}

From the current situation, in our country to supervision and consulting units at the same time with the construction project investment decision-making stage, design stage, bidding stage, the construction phase of the supervision capacity is still more difficult. The reason is that we lack the compound talents, so our country should increase the training and retraining of talents, and create a fair and competitive environment for them. Although Chinese project management level is still relatively low, and the developed countries there is a big gap, but I believe that with the project management laws and regulations to establish and improve the construction industry management system deepening the deepening of reform, fair competition in the market environment the gradual formation. Chinese project management level will have a big development.

\section{References}

[1] Huang Jianbai, Zhu Xuehong, Zhong Meirui. The game theory of bidding strategy in bidding and bidding activities [J]. Building Technology, 2006 (01)

(2) Wang Feng, Mao Lei, Wang Zhilei. Study on Game Theory in Project Bidding [J]. Journal of Nantong Vocational College, 2005 (04)

[3] Su Yingsheng, Wang Xianyu. Application and development of game theory [J] .Marketing Modernization, 2005 (29)

[4] Zhu Yijun. The construction project owners of the anti-claims management [J]. China Science and Technology Information, 2005 (16)

[5] Zhang Wei. Problems in Construction Contract Management and Its Countermeasures [J]. Liaoning Transportation Science and Technology, 2005 (03)

[6] Yan Yu. Construction project construction contract management [J]. Shanxi Architecture, 2004 (11) 